measurement was calculated for each study, along with standard deviations for each data set. The mean weighted bias was subsequently calculated using the formula (Bias $\times \mathrm{N}) / \mathrm{N}$

Results Mean weighted bias for the populations studied was $0.06 \mathrm{kPa}( \pm 2 \mathrm{SD} 2.40 \mathrm{kPa})$.

Discussion Patients with hypercapnoeic respiratory failure undergoing non-invasive ventilation (NIV) require regular measurements of $\mathrm{PCO}_{2}$ and $\mathrm{pH}$ status in order to optimise treatment. The current gold standard for measurement of $\mathrm{PCO}_{2}$ is arterial blood gas sampling. In critical care environments this necessitates placement of an indwelling arterial catheter, a painful procedure which carries a risk of complications including thrombotic occlusion, distal ischaemia, infection and pseudoaneurysm formation. Whilst accurate, arterial $\mathrm{PCO}_{2}$ measurement provides a single, static reading of an inherently dynamic process in the context of hypercapnoeic respiratory failure.

Transcutaenous $\mathrm{PCO}_{2}$ monitoring may prove a suitable and reliable non-invasive method for analysing partial pressure of carbon dioxide, with good approximation to arterial values. Our results suggest that transcutaneous $\mathrm{CO}_{2}$ monitoring may be used as a reliable surrogate to arterial $\mathrm{CO}_{2}$ measurements in specific patient populations undergoing NIV. However, variance is wide and further studies are needed to establish whether $\mathrm{PtcCO}_{2}$ is a sufficiently accurate marker on which to base treatment decisions.

\section{P182 COPD: IS IT ALL IN VEIN?}

E Sur; Monklands Hospital, Airdrie, Scotland

\subsection{6/thoraxjnl-2013-204457.334}

Introduction \& Objectives In patients with COPD, an arterial blood gas $(\mathrm{ABG})$ is considered the gold standard method of directly measuring serum $\mathrm{pH}, \mathrm{pO}_{2}, \mathrm{pO}_{2}$ and calculating bicarbonate $\left(\mathrm{HCO}_{3}\right)$ levels. These values allow the assessment of a patient's acid base status and adequacy of ventilation and oxygenation. The aim of this study was to identify if a venous blood gas can accurately reflect an arterial blood gas in determining the ventilatory function of patients presenting with acute exacerbations of COPD.

Methods This prospective observational study was conducted in a Scottish urban ED. All consecutive patients presenting with acute exacerbations of COPD were eligible. An ABG was taken from each patient, as deemed necessary by the treating physician, along with a venous gas at the time of venepuncture. Pearson's correlation coefficient and Bland Altman analysis methods were used to identify correlation and agreement between the arterial and venous data sets.

Results 68 paired samples were obtained over a two month period. Correlation was strong $(\mathrm{r}=0.953)$ between arterial and venous $\mathrm{pH}$. Bland Altman analysis showed an average difference (bias) of 0.017 , with 95\% limits of agreement (LOA's) of -0.052 to 0.087. Arterial and venous values for $\mathrm{HCO}_{3}$ were also strongly correlated $(\mathrm{r}=0.914)$. The agreement was $0.834 \mathrm{mmol} / \mathrm{l}$ with $95 \%$ LOA's of -4.82 to $3.15 \mathrm{mmol} / \mathrm{l}$. Despite arterial and venous $\mathrm{pCO}_{2}$ strongly correlating $(\mathrm{r}=0.973)$, the agreement bias was $4.66 \mathrm{mmHg}$ with $95 \%$ LOA's of -4.94 to $14.26 \mathrm{mmHg}$. Arterial hypercarbia, defined as $\mathrm{pCO}_{2}>45$ $\mathrm{mmHg}$, was present in 31 patients (46\%). All cases of arterial hypercarbia were detected on venous blood gas sampling using a $\mathrm{pCO}_{2}$ screening cut-off of $45 \mathrm{mmHg}$. This was found to be $100 \%$ sensitive (95\% CI $89-100 \%)$ and $86 \%$ specific (95\% CI 71-95\%).
Conclusion There is a strong correlation between arterial and venous $\mathrm{pH}, \mathrm{pCO}_{2}$ and $\mathrm{HCO}_{3}$. Agreement between $\mathrm{pH}$ and $\mathrm{HCO}_{3}$ is acceptable enough to substitute a venous blood gas value for an arterial blood gas value. However, venous $\mathrm{pCO}_{2}$ does not agree with arterial $\mathrm{pCO}_{2}$, therefore cannot be substituted. A venous $\mathrm{pCO}_{2}$ screening cut-off of $45 \mathrm{mmHg}$ has $100 \%$ sensitivity in detecting arterial hypercarbia. Had a venous blood gas been performed initially, 47\% of ABG's could be avoided in these patients.

\section{P183 AN OFF-LINE END-TIDAL BREATH SAMPLING METHOD IN ANAESTHETISED PATIENTS WITH ANALYSIS BY SELECTED ION FLOW TUBE MASS SPECTROMETRY}

${ }^{1} \mathrm{SC}$ Sturney, ${ }^{2} \mathrm{MK}$ Storer, ${ }^{3} \mathrm{GM}$ Shaw, ${ }^{4} \mathrm{RR}$ Kennedy, ${ }^{5} \mathrm{DE}$ Shaw, ${ }^{1} \mathrm{MJ}$ Epton; ${ }^{1}$ Respiratory Services, Christchurch Hospital, Christchurch, New Zealand; ${ }^{2}$ Syft Technologies Ltd, Christchurch, New Zealand; ${ }^{3}$ Department of Intensive Care Medicine, Christchurch Hospital, Christchurch, New Zealand; ${ }^{4}$ Department of Anaesthesia, Christchurch Hospital, Christchurch, New Zealand; ${ }^{5}$ Nottingham Respiratory Research Unit, Nottingham City Hospital, Nottingham, United Kingdom ${ }^{5}$

\subsection{6/thoraxjn-2013-204457.335}

Introduction Monitoring of breath volatiles could provide noninvasive rapid assessment of metabolic stress, inflammation and intravenous anaesthetic drug concentrations in anaesthetised patients. This study was designed to validate an off-line single breath end-tidal sampling method with analysis by selected ion flow tube mass spectrometry (SIFT-MS). Exhaled acetone was used as a model compound due to its abundance in breath and ease of measurement.

Methods End-expiratory breath samples from 22 healthy, nondiabetic, elective and semi-elective surgical patients were collected into Tedlar ${ }^{\circledR}$ bags via a T-piece adjacent to the endotracheal tube. The effects of different breathing systems, the breathing circuit filter, and consequences of altering the inspiratory gas flow rate and adjustable pressure limiting (APL) valve on exhaled acetone concentrations were explored in subgroups of these patients.

Results Median exhaled acetone concentration was $738 \mathrm{ppb}$ (range 257-6594 ppb) for samples collected on the patient side of the circuit filter with the APL valve open (usual position) ( $\mathrm{n}=22$ ). Median intra-subject coefficient of variation for exhaled acetone concentration using this method was $8.3 \%$ (interquartile range 6.9-14.5\%). Higher inspiratory but not exhaled acetone concentrations were seen when using the ADU Carestation compared to the Aysis Carestation anaesthesia machines (median inspiratory concentration $276 \mathrm{ppb} v 131 \mathrm{ppb}$, $\mathrm{p}=0.0005$; median exhaled concentration $630 \mathrm{ppb}$ $513 \mathrm{ppb}$, $\mathrm{p}=0.95$ ). Altering the inspiratory gas flow rate did not significantly affect exhaled acetone concentration; however APL valve closure resulted in a reduction in exhaled acetone concentration. Higher concentrations of acetone were measured in breath samples collected from the patient side of the circuit filter, since collection of samples after the filter resulted in dilution by deadspace air. Breath acetone concentration was related to plasma acetone $\left(\mathrm{r}_{\mathrm{s}}=0.80, \mathrm{p}<0.0001\right)$ and plasma betahydroxybutyrate concentrations $\left(r_{s}=0.49, \mathrm{p}=0.029\right)$.

Conclusions This non-invasive method of end-tidal breath collection in anaesthetised patients is reproducible for the analysis of acetone and is suitable for repeated sampling. With appropriate validation, the same method could be applied to the collection of other volatiles in the breath of intubated and ventilated patients, making it possible to investigate the concentrations of other potential biomarkers in this patient group. 